morbidity and mortality - though, for reasons given above, this is not supported by our results.

Roughly three cardiac abnormalities per 1000 live births present in infancy, according to the New England regional infant care programme and a similar, more recent report from the Brompton Hospital. ${ }^{12}{ }^{13}$ Examination of the forms of congenital heart disease reported by these surveys suggests an anticipated detection rate of two abnormalities per 1000 by evaluation of the four chamber view alone. A screening programme would not detect all congenital heart disease but should detect over $60 \%$ of severe structural heart disease that presents in the first year of life.

We believe that extension and organisation of teaching is now warranted. This would not necessitate a change in resources or personnel at the peripheral level. Such a programme has recently been reported from France (L Fermont $e t$ al, paper delivered to the Second World Congress of Pediatric Cardiology, New York, 1985). In that study obstetricians were taught to recognise the four chamber view. In two years 20000 pregnancies were screened with the detection of 39 structural cardiac abnormalities. This represents a detection rate of two abnormalities per 1000 pregnancies. Our experience suggests that such a screening programme would not result in larger numbers of anxious patients being needlessly referred for a second opinion, as in nearly all of our referrals for "suspected congenital heart disease" the condition was confirmed. Even the figure from the French study of $10 \%$ positivity is acceptable, as reassurance may authoritatively be given by the specialist centre. False positive results by the referral centre should be extremely uncommon. In a series of 2500 patients seen by us over six years no major false positive prediction was made.

A prenatal cardiac screening programme would have profound implications for the practice and organisation of paediatric cardiology in the future if it became widespread. Close cooperation with an obstetric unit, preferably in the same hospital as the paediatric cardiology centre, and skill in fetal echocardiography would become an essential part of the paediatric cardiology service.
In summary, prenatal cardiac screening is already in progress and could simply be extended by an organised teaching drive. The far reaching implications of such a programme, however, should not be overlooked.

We thank all cooperating obstetric units, King's College Hospital ultrasound unit in particular, and the British Heart Foundation for support to LDA, DCC, and SKC.

\section{References}

1 Forfar JO, Arneil GC, eds. Demography, vital statistics and the pattern of disease in childhood. In: Texibook of paediatrics. 2nd ed. Edinburgh. Churchill Livingstone, 1978:24.

2 Keith JD, Rowe RD, Vlad P. Heart disease in infancy and childhood. 3rd ed. New York: Macmillan Publishing Co Inc, 1978:9.

3 Kleinman CS, Donnerstein RL, Devore GT, et al. Fetal echocardiography for evaluation of in utero congestive heart failure. $N$ Engl 7 Med 1982;10:568-75

4 Allan LD, Crawford DC, Anderson RH, Tynan MJ. Echocardiographic and anatomical correlate in fetal congenital heart disease. Br Heart $\mathcal{O} 1984 ; 52: 542-8$.

5 Stark J, Smallhorn H, Huhta J, et al. Surgery for congenital heart defects diagnosed with crosssectional echocardiography. Circulation 1983;68(suppl II): 129-34.

6 Rice MJ, Seward JB, Hagler DJ, et al. Impact of two-dimensional echocardiography on the management of distressed newborns in whom cardiac disease is suspected. Am f Cardiol 1983;51:288-95.

7 Allan LD, Tynan MJ, Campbell S, Wilkinson JL, Anderson RH. Echocardiographic and anatomical correlates in the fetus. Br Heart $\mathrm{f} 1980 ; 44: 445-51$.

Royal College of Obstetrics and Gynaecology Working Party on Routine Ultrasound Examination in Pregnancy. Report. London: RCOG $1984: 24$.

in Pregnancy. Report. London: RCOG, 1984:24.
de Brux JL, Zannini L, Binet JP, et al. Tricuspid atresia. Results of treatment in 115 children 7 Thorac Cardiovasc Surg 1983;85:440-6.

10 Fontan F, Deville C, Quaegebeur J, et al. Repair of tricuspid atresia in 100 patients. 7 Thorac Cardiovasc Surg 1983;85:647-60.

11 Miller RA, Seratto M. Long term evaluation of the Fontan operation for tricuspid atresia. In Syamasundar Rao P, ed. Tricuspid atresia. New York: Futura Press, 1982:293-307.

12 Fyler DC, Buckley LP, Hellenbrand WE, Cohn HE. Report of the New England regional infan care program. Pediatrics 1980;65:375-461.

13 Scott DJ, Rigby ML, Miller GAH, Shinebourne EA. The presentation of symptomatic hear disease in infancy based on 10 years' experience (1973-1982). Implications for the provision of services. Br Heart f 1984;52:248-57.

(Accepted 16 April 1986)

\title{
Nursing dependency in registered nursing homes and long term care geriatric wards in Edinburgh
}

\author{
ANN E CAPEWELL， WILLIAM R PRIMROSE， CELIA MACINTYRE
}

\begin{abstract}
There has been growing interest and public investment in registered nursing homes, apparently based on the assumption that these homes are the private equivalent of hospital long term care. We have tested this hypothesis in a survey comparing $\mathbf{4 0 0}$ patients in 18 registered nursing homes with 217 patients in 11 geriatric long term care wards in Edinburgh. The nursing home patients formed a distinct and separate group: $362(92 \%)$ were women, $392(98 \%)$ were single or widowed, and $358(90 \%)$ were
\end{abstract}

\section{Longmore Hospital, Edinburgh EH9 1S}

ANN E CAPEWELL, BS, MRCP, senior registrar in geriatric medicine

Eastern General Hospital, Edinburgh

WILLIAM R PRIMROSE, MRCGP, MRCP, senior registrar in general and geriatric medicine

Medical Computing and Statistics Unit, University of Edinburgh CELIA MACINTYRE, MSC, medical statistician

Correspondence to: Dr Capewell. self financing, whereas in the geriatric long term care group 148 $(68 \%)$ were women and $35(16 \%)$ were still married. Patients in nursing homes were also far less dependent than those in geriatric long term care wards $(p<0.005)$.

This study suggests that there may be large differences between the patients in these two types of institution, particularly with regard to nursing dependency. This finding has important implications in the future planning of long term places for the dependent elderly.

\section{Introduction}

During the past five years there has been a $21 \%$ increase in the number of registered nursing homes catering for medical, geriatric, and convalescent patients. ${ }^{1}$ The changes in the amount of financial help available from the Department of Health and Social Security and, in particular, the large rise in November 1983 have contributed to this growth ${ }^{2}$; it has also been encouraged politically by an official emphasis on exploring the wider use of the private and voluntary sector. ${ }^{3}$ This increase in the number of registered nursing homes has stimulated intense debate concerning their role in the overall 
provision of places for long stay geriatric and psychogeriatric patients. ${ }^{+}$

Registered nursing homes already provide a notable proportion of the beds used by the disabled elderly, ${ }^{56}$ as do private and local authority residential homes. ${ }^{7-4}$ The number of very elderly people (aged over 85) will continue to increase until the turn of the century and beyond, ${ }^{10}$ and it is on this age group that the major burden of disability falls. "1: Increasing pressure on hospital beds is thus inevitable, ${ }^{12}$ and it has therefore been suggested that the nursing home sector could expand to meet this demand. ${ }^{3}$ It has also been suggested that nursing homes might have many advantages over long term geriatric wards, being smaller, cheaper to run, and in many cases nearer to relatives. ${ }^{1+}$ Three nursing homes have already been set up by the Department of Health and Social Security on an experimental basis to determine whether such homes could provide an alternative to geriatric long stay care. ${ }^{14}$

There is, therefore, growing interest and public investment by the Department of Health and Social Security in private nursing homes. ${ }^{+}$These developments have occurred despite the lack of studies of patients in nursing homes and in particular of how their levels of nursing dependency compare with those patients receiving hospital care. ${ }^{615} 16$

We have therefore studied patients in both registered nursing homes and long stay geriatric wards in Edinburgh and have assessed their levels of nursing dependency to determine whether these two groups of patients are actually comparable.

\section{Methods}

Between March and November 1984 we identified all registered nursing homes in Edinburgh catering for medical, convalescent, or geriatric patients. Permission to study each nursing home was sought from the owner or manager by us (AEC and WRP) and agreement was also obtained from each patient's general practitioner. We interviewed the nurse in charge in each nursing home using a standardised questionnaire, recording the personal details of each patient and the purpose of their stay. Using information obtained from the nursing staff, we assessed their degree of independence in the activities of daily living and their usual mental state. These assessments of independence were related to the abilities of the patient in the home when using all appropriate available aids such as a plate guard or a walking frame.

During the same period 217 patients from 11 long term care geriatric wards in Edinburgh hospitals were reviewed, and comparable information was recorded by the nursing staff using the same questionnaire. The data obtained were analysed using the BMDP statistical package, ${ }^{17}$ and differences between the subgroups were tested by the $\chi^{2}$ method or a test for trend where appropriate. ${ }^{1 \times 19}$

During our visit we also noted the weekly nursing home fee and assessed the facilities available and the patient's access to these facilities. This information, including details of social contact, duration of stay, Department of Health and Social Security supplementation, and source of admission, is reported elsewhere. ${ }^{21}$

\section{Results}

There were 21 registered nursing homes with a total of 486 places catering for medical, geriatric, or convalescent patients in Edinburgh at the time of our survey. None were specifically designated as being psychiatric or psychogeriatric nursing homes; many, however, were willing to accept suitable patients from psychogeriatric units. Eighteen of the 21 nursing homes (with 400 patients) cooperated in this study. Of the 400 patients, 386 $(97 \%)$ were long term, the remainder being convalescent or admitted for terminal care. On the 11 geriatric wards all 217 patients had been accepted for long term care.

Costs - The average weekly charge in the nursing homes was $£ 205$ ( $£ 130$ $350)$ for a single room and $£ 149$ ( $£ 105-200)$ for a shared one. This sum excluded possible extra charges to the patient for toiletries, laundry, chiropody, physiotherapy, hairdressing, etc, and the cost to the National Health Service for medication and primary medical care. The mean cost per patient in Scottish long stay geriatric units controlled by a geriatrician in 1983-4 was $£ 222$ per week. ${ }^{21}$

Age, sex, and marital status-In the nursing homes most patients were women $(368 ; 92 \%)$ with a mean age of 86 years; only $32(8 \%)$ were men, mean age 83 years. In contrast $69(32 \%)$ of the long term patients were men and their mean age ( 80 years) was lower $(\mathbf{p}=0.05)$ (table I). Over $38 \%$ of the nursing home patients were single compared with $23 \%$ of long term patients on geriatric wards $(p<0.01)$, and this was not simply due to age and sex differences between the two groups. ${ }^{22}$

TABLE I-Age, sex, and marital status of patients in nursing homes and long term care

\begin{tabular}{lcc}
\hline & $\begin{array}{c}\text { Nursing homes } \\
(\mathbf{n}=400)\end{array}$ & $\begin{array}{c}\text { Long term care } \\
(\mathbf{n}=217)\end{array}$ \\
\hline $\begin{array}{l}\text { Age and sex } \\
\text { Men }(\text { mean age; range) }\end{array}$ & $32(82 \cdot 6 ; 64-101)$ & $69(79 \cdot 8 ; 60-101)$ \\
$\quad$ Women (mean age; range) & $368(85 \cdot 5 ; 52-104)$ & $148(84 \cdot 9 ; 66-99)$ \\
Total (mean age) & $400(85 \cdot 3)$ & $217(83 \cdot 37)$ \\
Marital status & $154(38 \cdot 5)$ & $50(23)$ \\
$\quad$ Singlef & $238(59 \cdot 5)$ & $132(61)$ \\
Widowed or divorced & $8(2)$ & $35(61)$ \\
Married & & \\
& & \\
\hline
\end{tabular}

${ }^{\star} \mathrm{p}=0.05 .+\mathrm{p}<0.01$.

Dependency - For each separate measure of nursing dependency (feeding, dressing, continence, mobility, and mental impairment) the nursing home patients were far less dependent than the hospital long term group, all the differences in dependency being highly significant $(p=0.005)$ (see tables IIIV). For the patients who were incontinent of urine there was much less use made in the nursing homes of incontinence aids such as pads and pants, and in several homes the nursing staff commented on the difficulty in obtaining such aids for their patients. The overall assessment of the nursing home patients showed that $112(28 \%)$ appeared to meet the usual criteria for local authority residential care, being continent, freely mobile on the flat, able to dress with minimal assistance, and needing supervision only because of mental impairment.

\section{Discussion}

Fewer than $6 \%$ of old age pensioners live in an institution, ${ }^{23}$ and, although this proportion is small, the actual numbers are large and rising steadily. As the numbers of the very elderly grow, the pressures on institutional beds will increase. ${ }^{13}$ The proportion of these beds that are located in hospitals rather than in residential homes varies throughout the United Kingdom, being higher in Scotland. ${ }^{23}$ One might expect, therefore, that the overall dependency level of long term geriatric patients would be even higher south of the border.

The concept of the nursing home, a small unit close to relatives and running at low cost, is attractive. ${ }^{1+}$ The establishment of three experimental National Health Service nursing homes by the government and the Department of Health and Social Security's supplementation for patients entering private and voluntary homes could be seen as a commendable attempt to find an economical way of lessening the pressure on long term beds. Costs can be compared, however, only if similar facilities are provided for patients with similar needs. Our study has shown that for each measure of nursing dependency the nursing home patients were far less dependent than

TABLE II-Feeding, dressing, and mental impairment

\begin{tabular}{|c|c|c|}
\hline & $\begin{array}{l}\text { Nursing homes } \\
\quad(n=400)\end{array}$ & $\begin{array}{l}\text { Long term care } \\
\qquad(\mathrm{n}=217)\end{array}$ \\
\hline \multicolumn{3}{|l|}{ Dependency for feeding $(\%)^{\star}$} \\
\hline Independent & $321(80)$ & $69(32)$ \\
\hline Some help & $35(9)$ & $106(49)$ \\
\hline Totally dependent & $44(11)$ & $+2(19)$ \\
\hline \multicolumn{3}{|l|}{ Dependency for dressing $(\%) \dagger$} \\
\hline Independent & $114(29)$ & $12(5 \cdot 5)$ \\
\hline Some help (fastening & $98(24)$ & $50(23)$ \\
\hline Totally dependent & $188+47$ & 15572 \\
\hline \multicolumn{3}{|l|}{ Degree of mental impairment $(\%) \ddagger$} \\
\hline None & $108(27)$ & $38(17 \cdot 5)$ \\
\hline Mild (occasionally disorientated) & $101(25)$ & $49(22 \cdot 5)$ \\
\hline Moderate (disorientated but able to converse) & $82(20)$ & $59(27)$ \\
\hline $\begin{array}{l}\text { Severe (unable to converse or with } \\
\text { severe behavioural disturbance) }\end{array}$ & $109(27)$ & $71(33)$ \\
\hline
\end{tabular}

*Difference in dependency between groups $z=9 \cdot 2, p<0 \cdot 001$. + Difference in dependency between groups $z=7 \cdot 0, p<0 \cdot 001$. $\ddagger$ Difference in dependency between groups $z=2 \cdot 8, p=0 \cdot 005$. 
TABLE III-Mobility

\begin{tabular}{|c|c|c|}
\hline & $\begin{array}{l}\text { Nursing homes } \\
\quad(n=400)\end{array}$ & $\begin{array}{l}\text { Long term care } \\
\quad(n=217)\end{array}$ \\
\hline \multicolumn{3}{|l|}{ On and off bed } \\
\hline Independent & $203(51)$ & $16(7 \cdot 4)$ \\
\hline Some help needed & $67(17)$ & $47(22)$ \\
\hline Dependent or bed bound or both & $130(32)$ & $154(71)$ \\
\hline Difference in dependency between groups & \multicolumn{2}{|c|}{$\mathrm{z}=10.8, \mathrm{p}<0.001$} \\
\hline \multicolumn{3}{|l|}{ On and off chair } \\
\hline Independent & $225(56)$ & $33(15)$ \\
\hline Some help needed & $55(14)$ & $46(21)$ \\
\hline Dependent or chair bound or both & $120(30)$ & $138(64)$ \\
\hline Difference in dependency between groups & \multicolumn{2}{|c|}{$z=9 \cdot 6, p<0.001$} \\
\hline \multicolumn{3}{|l|}{ On flat with walking aid } \\
\hline Independent & $211(53)$ & $31(14)$ \\
\hline Some help needed & $61(15)$ & $50(23)$ \\
\hline Dependent & $79(20)$ & $90(41)$ \\
\hline Cannot walk at all & $49(12)$ & $46(21)$ \\
\hline Difference in dependency between groups & \multicolumn{2}{|c|}{$\mathrm{z}=8 \cdot 3, \mathrm{p}<0.001$} \\
\hline
\end{tabular}

TABLE IV-Incontinence

\begin{tabular}{lcc}
\hline & $\begin{array}{c}\text { Nursing homes } \\
(\mathrm{n}=400)\end{array}$ & $\begin{array}{c}\text { Long term care } \\
(\mathrm{n}=217)\end{array}$ \\
\hline Urinary incontinence & $179(45)$ & $32(15)$ \\
Never & $20(5)$ & $16(7)$ \\
Occasionally at night & $77(19)$ & $76(35)$ \\
Occasionally day or night & $124(31)$ & $93(43)$ \\
Frequent or catheterised & $\mathrm{z}=6 \cdot 4, \mathrm{p}<0 \cdot 001$ \\
Difference in dependency between groups & $277(69)$ & $64(29)$ \\
Urine-aids used & $105(26)$ & $108(50)$ \\
None (apart from bottles, etc) & $18(4)$ & $27(12)$ \\
Pads or pants & 0 & $18(8)$ \\
Catheter & $296(74)$ & $84(38)$ \\
Other (for example, urodome) & $32(8)$ & $68(31)$ \\
Faecal incontinence & $72(18)$ & $65(30)$ \\
Never & $z=6 \cdot 7, \mathrm{p}<0 \cdot 001$
\end{tabular}

* For those who were incontinent of urine, less use was made in the nursing homes of incontinence aids.

$\chi^{2}=33.8, p<0.001$

those in long term geriatric care. They also appeared to form a distinct group, being predominantly very elderly single or widowed women who were self financing. Similar observations were made 25 years ago by Woodroffe and Townsend. ${ }^{15}$ More recently Wade et al reviewed patients at home and in several institutions. Their study was funded by the Department of Health and Social Security and conducted with the aim of considering alternatives to long term hospital care. They reported a less striking difference in dependency between patients in registered nursing homes and those in geriatric wards. Unfortunately, four of the eight nursing homes studied were in a different geographical area from the rest of those investigated and local conditions may have influenced their findings. In addition, the comparison was made with patients who had been on geriatric wards for three months or more, some of whom were waiting for alternative accommodation rather than staying for long term care. ${ }^{10}$

Our finding that registered nursing homes in Edinburgh do not cater solely for patients with high nursing dependency does not imply that these homes have no role in the provision of long term places for the very disabled elderly. Many old people know that as time passes their needs may change and are reassured to know that nursing homes should be able to continue to care even if they become very dependent, thus avoiding yet another distressing move. It is the policy of the flexible provision of appropriate care which makes the Brendoncare initiative so attractive. ${ }^{24}$

The decision to enter a nursing home is often determined by social considerations, and there is no requirement for a medical opinion. Even for those receiving Department of Health and Social
Security supplementation the only formal assessment is a financial one. There is no requirement to show nursing dependency or to screen for remediable conditions. The relatively small number receiving supplementation in our survey $(42 ; 10 \%)$ differed little in their dependency from the remaining nursing home patients. ${ }^{20}$

In 1981 there were 74500 people in Edinburgh aged 65 and over, ${ }^{22} 486$ nursing home places thus provided 6.5 beds per 1000 for this age group. In addition, there were 630 designated geriatric long term care beds, 650 places in local authority homes, and 650 places in private and voluntary old people's homes. The nursing homes, therefore, provided about $20 \%$ of long term places, excluding those in hotels, hostels, and psychiatric wards. With a growing proportion of nursing home patients receiving financial supplementation, it is important to ensure that these resources are not misused.

Several studies have shown that very disabled people can be found at home ${ }^{11}$ and in private ${ }^{6}$ and local authority residential care,${ }^{89}$ as well as in nursing homes and on geriatric and psychogeriatric wards. There is also a large overlap in patient dependency between these settings. ${ }^{25}$ The policy of the three experimental National Health Service nursing homes, apparently modelled on existing private and voluntary homes, has been to admit the same type of patient as those admitted to geriatric long term care. Our study, however, does not support the assumption that patients in registered nursing homes and geriatric long term care wards have similar degrees of nursing dependency. Any planning of long term places for these elderly patients that includes nursing homes as they exist at present should perhaps be reconsidered.

We thank the nursing home managers and ward sisters for their interest and cooperation, Drs HM MacLeod and W C Cockburn for advice, Mrs G Dickson for secretarial help, and the Lothian Health Board for financial assistance with this study.

\section{References}

1 Registered Nursing Homes Association Reference Book. London: Registered Nursing Homes Association, 1980 and 1985

2 Department of Health and Social Security. Supplementary benefit (requirements, resources and single payments) amendment regulations. London: HMSO, 1983. (S1 1399.

3 Department of Health and Social Security. Care in action. A handbook of priorities for the personal social services in England. London: HMSO, 1981.

4 Anonymous. Private nursing homes and the old [Editorial]. Lancet 1985;ii:1338-40.

4 Anonymous. Private nursing homes and the old [Editorial]. Lancet $1985 ;$ ii: $1338-40$.
5 Primrose WR. Capewell AE. Registered nursing home places catering for the elderly within Primrose WR, Capewell AE. Registered nursing ho
Scotland. Scoltish Health Bulletin 1986; March:81-4.

6 Wright K. Contractual arrangements for geriatric care in private nursing homes. York: University of York Centre for Health Economics, 1985. (Discussion Paper 4.

7 Andrews K. Private rest homes in the care of the elderly. Br Med F 1984;288: 1518-20

8 Booth T, Barritt A, Berry S, Martin DN, Mellotte C, Stone S. Levels of dependency in local authority homes for the elderly. I Epidemiol Community Health 1982;36:53-7.

9 Masterton G, Holloway EM, Timbury GC. Role of local authority homes in the care of the dependant elderly: a prospective study. Br Med f 1981;283:523-4

10 Craig J. The growth of the elderly population. Population Trends 1983;32:28-34.

11 Hunt A. The elderly at home. (OPCS social services division.) London: HMSO, 1978.

12 Grundy E. Mortality and morbidity amongst the old. Br Med 7 1984;288:663-4.

13 Grundy E, Arie T. Falling rate of provision of residential care for the elderly. $\mathrm{Br}$ Med $\mathrm{J}$ 1982;284:799-802.

14 Department of Health and Social Security. The experimental National Health Service nursing homes for elderly people - an outline. London: HMSO, 1983.

15 Woodroffe E. Townsend P. Nursing homes in England and Wales. London: The National Cooperation for the care of old people, 1961.

16 Wade B, Sawyer L, Bell J. Dependency with dignity. London: Bedford Square Press, 1983.

17 Dickson WD. BMDP Statistical Software. Los Angeles: University of California Press, 1983.

18 Armitage P. Statistical methods in medical research. Oxford: Blackwell Scientific Publications, 1971

19 Cox DR. Analysis of binary data. London: Chapman and Hall, 1970

20 Primrose WR, Capewell AE. A survey of registered nursing homes within the city of Edinburgh. 7 $R$ Coll Gen Pract 1986;36:125-8.

21 Scottish Home and Health Department. Scottish Health Service costs for the year ended 31 st March 1984. Edinburgh: HMSO.

22 Office of Population Censuses and Surveys. Small area statistics: Edinburgh city district. Edinburgh: General Register Office (Scotland), 1981.

23 Scottish Home and Health Department and the Scottish Education Department. Changing patterns of care. Report on services for the elderly in Scotland. Edinburgh: HMSO, 1980.

24 Smith T. Brendoncare: an initiative in the care of the elderly. Br Med f 1983;289:909-10.

25 Charlesworth A, Wilkin D. Dependency among old people in geriatric wards, psychogeriatric wards and residential homes, 1977-1981. (Research Report Number 6.) University of Manchester: and residential homes, $1977-1981$. (Research Report Number

(Accepted 24 March 1986) 